different speech sound if it is associated with a different speech source. ${ }^{3}$ This latter observation is particularly relevant to the earliest stage of language learning - the child will be unable to make progress if he cannot equate his sounds with those made by the adults around him-and possibly to some cases of language impairment in the adult since if this ability to abstract is absent there might be no speech comprehension presented with otherwise normal hearing.

In the fairly near future this background knowledge will prov:de the basis for a speech pattern audiometry which will be truly intermed:ate between the classical pure tone and speech audiometric tests. Though its test stimuli are computer-generated and far more complex than those which are at present used, they can be tape-recorded and used clinically with quite simple and reliable apparatus. In addition to this we can expect eventually to see the employment of speech therapy techniques which depend on the analysis and display of speech pattern features ${ }^{4}$ and the use of synthetic speech for the blind ${ }^{5}$ and as a prosthetic speech aid for those who are entirely without expressive speech.

These technical developements which are l:kely to stem from the use of our present knowledge of speech patterns will probably be paralleled by an increase in our understanding of the mechanisms which underly the speech mode of perception. The experimental techniques which have made hemispheric specialization more accessible to measurement ${ }^{6}$ and those which are beginning to define the role of short-term auditory memory in speech processing ${ }^{7}$ may be capable of extension so that the process of speech pattern encoding itself is better understood.

This rather superficial survey will have achieved its purpose if I have at least indicated how audiometric stimuli could, tr advantage, be related to the nature of speech itself.-I am, etc.,

A. J. FOURCIN

Department of Phonetics and Linquistics,

University College

1 Cooper, F. S., Delattre, P. C., Liberman, A. M., Borst, J. M., and Gerstman, L. J., Ұournal ct the Acoustical Society of America, 1952, 24, Delattre, P. C., Liberman, A. M., and Cooper F. S., Fournal of the Acoustical Society of America, 1955, 27. 769. Transaction
Fourcin, A. J., I.E.E.E. Tration

and Electroacoustics 1968, AU-16. 65. Fourcin, A. J., and Abberton, E. R. M., Me

5 Nye, P. W., Hankins, J. D., Rand, T. Mattingly, I. G., and Cooper, F. S., Air Force Cambridge Research Laboratories, Special Reports 131 6 A. 3, p. 23 Cambridge, Massachusetts, 1972. Neuropsychologia, 1967, 5, 295. Neuropsychologia, 1967, 5, 295.
Conrad, R., British fournal of Psychology, 1964,
55, 75.

\section{Bronchospasm after Althesin \\ Anaesthesia}

SIR,-I read with interest the letter by Lt. Col. T. R. Austin and others (16 June, p. 661) in which it was assumed that Althesin was the drug responsible for bronchospasm occurring during anaesthesia. Apparently no tests were performed to substantiate this conclusion despite the simultaneous use of other drugs, including pancuronium. In a recent similar case, to be published in the British Fournal of Anaesthesia, bronchospasm occurred following the administration of pan- curonium and Althesin. Further investigations during anaesthesia and also by intradermal testing postoperatively showed conclusively that pancuronium and not Althesin was responsible for the bronchospasm. Anaesthesia is a complex situation and adverse reactions may be caused by any one of the drugs used, by drug interactions, or by other factors.-We are, etc.,

R. M. Clark Department of Anaesthesia

F. R. Ellis General Infirmary, Leeds

SIR,-In reply to Dr. M. J. Heslop's letter (30 June, p. 775) commenting on our report of a case of bronchospasm following the administration of Althesin and pancuronium (16 June, p. 661), may we say we were most interested to read of the case of bronchospasm following pancuronium, reported by Buckland and Avery. ${ }^{1}$ Until this latter report pancuronium had held an unblemished record over its five-year world wide use for not causing h:stamine release, even in susceptib.e laboratory animals in large dosage. ${ }^{2}$ As this information was not available at the time we felt that our patient's problem had probably been caused by the Althesin.

This correspondence emphasizes, we feel, the very real need for the kind of inquiry which Professor J. W. Dundee and Dr. R. S. J. Clarke are embarking upon, ${ }^{3}$ with a scientific evaluation of the extent of unusual reactions to anaesthetic drugs, and especially new anaesthetic drugs.

In reply to the final point in Dr. Heslop's letter we can only say we have issued the patient with a card pointing out the problem we encountered. The value of skin testing is not proved and there remain plenty of alternative agents should he need further anaesthetics.-We are, etc.,

T. R. Austin J. ANDERSON British Military Hospital J. RICHARDSON Rinteln, Germany

Buckland R. W., and Avery A. F., British fournal

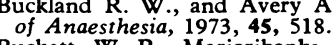

of Anaesthesia, 1973, 45, 518 .
Buckett, W. R., Marjoribanks, C. E. B., Marwick, F. A., and Morton M. B., British fournal of Pharmacology 1968, 32, 671.

Dundee, J. W., and Clarke, R. S. J., British fournal of Anaesthesia, 1973, 45, 304.

\section{Facial Sweating after Food in Diabetes}

SIR,-Dr. P. J. Watkins (10 March, p. 583) having told me about facial sweating after food in 1972, I specifically sought this sign in 200 consecutive patients at our diabetic clinic and found two similar cases.

The first patient was a woman aged 32 with severe insulin-dependent, unstable diabetes for six years with advanced retinopathy, nephropathy, gut neuropathy, and orthostatic hypotension. For two years she had suffered profuse facial and neck sweating after chewing but obtained no relief from anticholinergic drugs. The second patient was a 78-year-old woman with three months' history of thirst, polyuria, and vaginitis. She was thin, normotensive, apparently otherwise healthy, and nonketotic, with a fasting blood sugar of $180 \mathrm{mg}$ per $100 \mathrm{ml}$. Gustatory sweating was noticed within two weeks of the onset of polyuria. There was no other evidence of peripheral or autonomic disturbance and no pupillary changes or lesions of the chest or brachial plexus. After diet and four weeks of glibenclamide the glycosuria disappeared and the fasting blood sugar fell to $120 \mathrm{mg} / 100$ $\mathrm{ml}$ with disappearance of thirst, etc. Her gustatory sweating has continued, however, and is presumably her only evidence of diabetic autonomic neuropathy.

It is possible that "Watkins's sign" may be more common than has hitherto been realized.-I am, etc.,

A. FrEedMaN

Department of Medicine,

Prince of Wales Hospital,

Randwick, New South Wales

\section{Rootless Wanderers}

SIR,-Your leading article (7 July, p. 1) is very timely and I would like to make some further comment on it.

We psychiatrists working in the community have expressed for some time our very great concern over the lack of understanding by the legislators for the implementation of an efficient community psychiatrist service as part of the future comprehensive psychiatric set-up. The Local Authority Social Services Act 1970 unfortunately initiated the split between the hospital and community sectors of the service, and the proposed reorganization of the National Health Service will, I fear, finalize this dichotomy. The community sector of the psychiatric service plays an integral part in any overall psychiatric scheme, and one part cannot function efficiently without the other. The only way to build up such a service is, in my opinion to bring together all the psychiatric facilities, services, and personnel under one authority, the only logical one being the future health authority.

If it is proposed to run down and eventually phase out the pr"chiatric hospitals, as indeed appears to $b_{i}$ Government policy, then this can be atti upted only after, not before, efficient community psychiatric services have been established in the respective areas. Furthermore it should not be forgotten that the psychiatric units attached to district general hospitals equally require the help of the community psychiatric counterparts. So let us put the emphasis where it seems to fit best into the envisaged psychiatric service of the future-namely, to encourage the building up of appropriate community services under psychiatric guidance and management.-I am, etc.,

London N.15

U. P. SEIDAL

\section{Excretion Urography in Acute Renal Failure}

SIR,-We have read with great interest the very careful report of Dr. W. R. Cattell and others (9 June, p. 575) on urographic findings in acute renal failure. Over the past two years we have carried out a similar study on 25 oliguric patients without any obstructive disease. In 20 cases a diagnosis of acute tubular necrosis was made, based on the sudden onset of renal failure, the presence of an aetiological factor, typical urinary findings, and a typical clinical course including a diuretic phase and complete recovery. In five cases subacute glomerular or vascular disease was diagnosed on histological evidence (subacute glomerulonephritis in two, polyarteritis in two, and malignant 